\title{
Proportions of students who use various modes of transportation to and from school in a representative population-based sample of children and adolescents, 1999
}

\author{
Roman Pabayo $^{\mathrm{a}, *}$, Lise Gauvin ${ }^{\mathrm{b}}$ \\ ${ }^{a}$ Faculté de médecine, Groupe de recherche interdisciplinaire en santé and Médecine sociale et préventive, Université de Montréal, Canada H2V 4P3 \\ ${ }^{\mathrm{b}}$ Faculté de médecine, Department of Social and Preventive Medicine, Groupe de recherche interdisciplinaire en santé, \\ and Centre de recherche Léa-Roback sur les inégalités sociales de santé de Montréal, Université de Montréal, Canada H2V $4 P 3$
}

Available online 3 August 2007

\begin{abstract}
Objective. The purposes of this study were to describe the prevalence of modes of transportation to school and to identify socioeconomic correlates.

Methods. Proportions of students using different modes of transportation were estimated among a population-based sample of 3613 youth aged 9, 13, and 16 years who participated in the 1999 Quebec Child and Adolescent Health and Social Survey.

Results. Weighted analyses showed significant differences in the use of different modes of transportation to and from school across socioeconomic groups. For example, $40.3 \%, 15.2 \%$, and $13.0 \%$ of 9,13 , and 16 year olds walked to school. In addition, $1.2 \%, 11.3 \%$, and $13.8 \%$ of 9,13 , and 16 year olds used public transportation whereas $33.1 \%, 51.2 \%$, and $55.6 \%$ of 9 , 13 , and 16 year olds took the school bus to school; $14.3 \%, 7.3 \%$, and $5.0 \%$ of 9,13 , and 16 year olds were transported by car; finally, $10.7 \%, 14.1 \%$, and $11.7 \%$ of 9,13 , and 16 year olds indicated they used multiple modes of transportation. Girls, higher income of children, children of immigrants, and rural-dwelling children were less likely to walk to school.

Conclusion. Findings indicate that there are differing modes of transportation to and from school across socioeconomic groups. (C) 2007 Elsevier Inc. All rights reserved.
\end{abstract}

Keywords: Walking; Physical fitness; Child; Adolescent; Socioeconomic factors; Community surveys

\section{Introduction}

Physical activity is important for healthy growth and development and can track into adulthood thus resulting in chronic disease prevention (Story and Neumark-Sztainer, 1999; Malina et al., 2004). There are secular trends of declining physical activity among youth (Centers for Disease Control and Prevention, 1994, 1998) highlighting the need for opportunities for youth to be more physically active (Barnett et al., 2006; Malina et al., 2004). Active transportation to and from school,

\footnotetext{
* Corresponding author. Département de médecine sociale et préventive, 1420 boul. Mont-Royal, Montréal, Québec, Canada H2V 4P3. Fax: +1 5143435645.

E-mail addresses: roman.pabayo@umontreal.ca (R. Pabayo), lise.gauvin.2@umontreal.ca (L. Gauvin).
}

such as walking, is one potential opportunity for children to be physically active (Sirard et al., 2005; Heelan et al., 2005) and may contribute to preventing excess weight gain (Rosenberg et al., 2006). Proportions of children walking to and from school range from $4.2 \%$ to $25.0 \%$ (Sirard et al., 2005; Carlin et al., 1997; Ham et al., 2005; Martin and Carlson, 2005; Bricker et al., 2002; Salmon et al., 2005), but only two estimates are based on large population-based studies (Ham et al., 2005; Bricker et al., 2002). Findings have been inconsistent showing that boys are more likely to walk to school in comparison to girls (Merom et al., 2006), but not always (Carlin et al., 1997; Bricker et al., 2002), that younger children are more likely to walk to school (Martin and Carlson, 2005), that older children are more likely to walk to school (Merom et al., 2006; Bricker et al., 2002; Ham et al., 2005), and that Hispanic and/or Black children are more likely to walk to school (Bricker et al., 2002; McDonald, 2007). 
Unfortunately, little is known about the use of a variety of transportation modes. We therefore describe the proportion of children who walked, used public transit, were driven in a school bus or vehicle, or used multiple transportation modes to and from school. Estimates are stratified by age, sex, 1998 household income, urban versus rural settings, and parents' birthplace.

\section{Methods}

Data for this study were from the 1999 Quebec Child and Adolescent Health and Social Survey (QCAHS), which is a representative population-based community survey that sampled 3613 youths in the province of Quebec, Canada aged 9, 13, and 16 years old (Paradis et al., 2003).

\section{Sampling}

The QCAHS was a multistage, stratified, cluster sampling survey. The sampling frame consisted of the 1998 to 1999 Quebec Ministry of Education student roll, which contains name, date of birth, home address, and school attended of all students in Quebec. Independent samples were drawn for each age group. Response rates to the student questionnaire among the 9,13, and 16 year olds were $83.4,79.2$, and $77.6 \%$, and $70.1,68.8$, and $63.7 \%$ for the parent questionnaire (Paradis et al., 2003).

Ethics approval was obtained from the ethics committees of the Direction Santé Québec of the Institut de la statistique du Québec, the Ministère de l'éducation du Québec, and Ste-Justine's Hospital. Signed informed consent was obtained from parents and youths.

\section{Variables}

Socioeconomic data included sex, age, 1998 family income in Canadian dollars (CAD), and parents' birthplace. Schools were categorized as being located in an urban area if they were situated in one of Quebec's six Census Metropolitan areas designated by Statistics Canada (http://www.statcan.ca/) and in a rural area otherwise. Students were asked which mode of transportation to and from school they used most often. Response options were: school bus, walking, public transit, motor vehicle, or multiple modes of transportation. Copies of the questionnaires and data collection forms are available on the website of the Institut de la statistique du Québec (http://www.stat.gouv.qc.ca/ publications/sante/enfant-ado_pdf.htm\#questionnaires).

\section{Data analysis}

Estimation of the proportions of participants using different modes of transportation was weighted for design effects (Paradis et al., 2003) and then stratified by age, gender, urban vs. rural setting, 1998 household income, and parents' birthplace. Chi-square tests were performed to test for differences across strata.

\section{Results}

Descriptive statistics for the 3613 students who responded to the survey appear in Table 1. Overall, the sample was evenly divided across age and sex categories. About $60 \%$ of respondents lived in urban areas, one quarter had family incomes below $\$ 30,000(\mathrm{CAD})$, and just over $10 \%$ were offspring of at least one parent who was born outside of Canada. Use of different modes of transportation to school was as follows: walking $=23.3 \%$, using public transit $=8.5 \%$, taking school bus $=46.2 \%$, driven by motor vehicle $=9.0 \%$, or multiple modes $=12.1 \%$.
Table 1

Socioeconomic characteristics of youths participating in the 1999 Quebec child and adolescent health and social survey, Quebec, Canada

\begin{tabular}{lll}
\hline & $\begin{array}{l}\text { Unweighted proportion } \\
\text { of study population } \\
(n=3613)\end{array}$ & $\begin{array}{l}\text { Weighted proportion } \\
\text { of study population } \\
(n=3613)\end{array}$ \\
\hline Age & 35.1 & 35.1 \\
$\quad 9$ years & 32.8 & 32.8 \\
13 years & 32.1 & 32.1 \\
16 years & & \\
Sex & 49.2 & 50.7 \\
Male & 50.8 & 49.3 \\
Female & & 60.3 \\
Type of setting & 57.1 & 39.7 \\
Urban & 42.9 & 24.5 \\
Rural & & 41.2 \\
1998 household income & 25.3 & 34.3 \\
$\quad$ \$30,000 & 41.7 & 86.6 \\
\$30,000-\$60,000 & 33.0 & 5.7 \\
> \$60,000 & & 7.7 \\
Birthplace of parents & 87.6 & \\
Both parents born in Canada & \\
One parent born in Canada & 5.3 & \\
Both parents born outside & 7.0 & \\
Canada & & \\
\hline
\end{tabular}

Modes of transportation to school were associated with socioeconomic and demographic factors (see Table 2). Higher percentages of nine year olds walked $\left(\chi^{2}=317.10, p \leq 0.01\right)$ or were driven by $\operatorname{car}\left(\chi^{2}=70.14, p=0.03\right)$ to school in comparison to 13 and 16 year olds. Higher proportions of the two older age groups used public transportation $\left(\chi^{2}=141.38, p<0.01\right)$ and took the school bus $\left(\chi^{2}=142.07, p<0.01\right)$ in comparison to 9 year olds. The proportion of 13 year olds who used multiple modes of transportation was significantly higher $\left(\chi^{2}=7.20, p<0.05\right)$ than otherwise. Greater proportions of boys indicated that they walk to school in comparison to girls $\left(\chi^{2}=4.19, p<0.05\right)$. The proportions of urban students who walked $\left(\chi^{2}=7.67, p<0.01\right)$, take public transportation $\left(\chi^{2}=199.08, p<0.01\right)$, and who were driven $\left(\chi^{2}=42.19\right.$, $p<0.01)$ were higher in comparison to rural students. Conversely, the proportion of rural students who take the school bus to school $\left(\chi^{2}=178.31, p<0.01\right)$ was larger in comparison to urban-dwelling students. The proportion of students who walked to school was significantly higher among those whose income was less than $\$ 30,000 \quad\left(\chi^{2}=45.45\right.$, $p<0.01)$. The percentage of students who used public transportation $\left(\chi^{2}=16.48, p<0.01\right)$ was significantly lower among the students who had a household income between $\$ 30,000$ and $\$ 60,000$ in comparison to the higher and lower groups. The proportion of students who were driven to school was significantly higher among students whose 1998 household income was greater than $\$ 60,000$ in comparison to lower two income groups $\left(\chi^{2}=55.62, p<0.01\right)$. Proportions of students who walked $\left(\chi^{2}=8.02, p=0.03\right)$ and took the school bus $\left(\chi^{2}=62.88, p<0.01\right)$ were highest among children whose parents were born in Canada in comparison to children who had at least one parent born outside of Canada. Finally, proportions of students who take public transportation $\left(\chi^{2}=99.46, p<0.01\right)$, are driven by car $\left(\chi^{2}=26.16, p<0.01\right)$, 
Table 2

Weighted proportions of students, who walked, used public transportation, were driven in a school bus or car, or used multiple modes of transportation to and from school in the 1999 Quebec child and adolescent health and social survey, Quebec, Canada

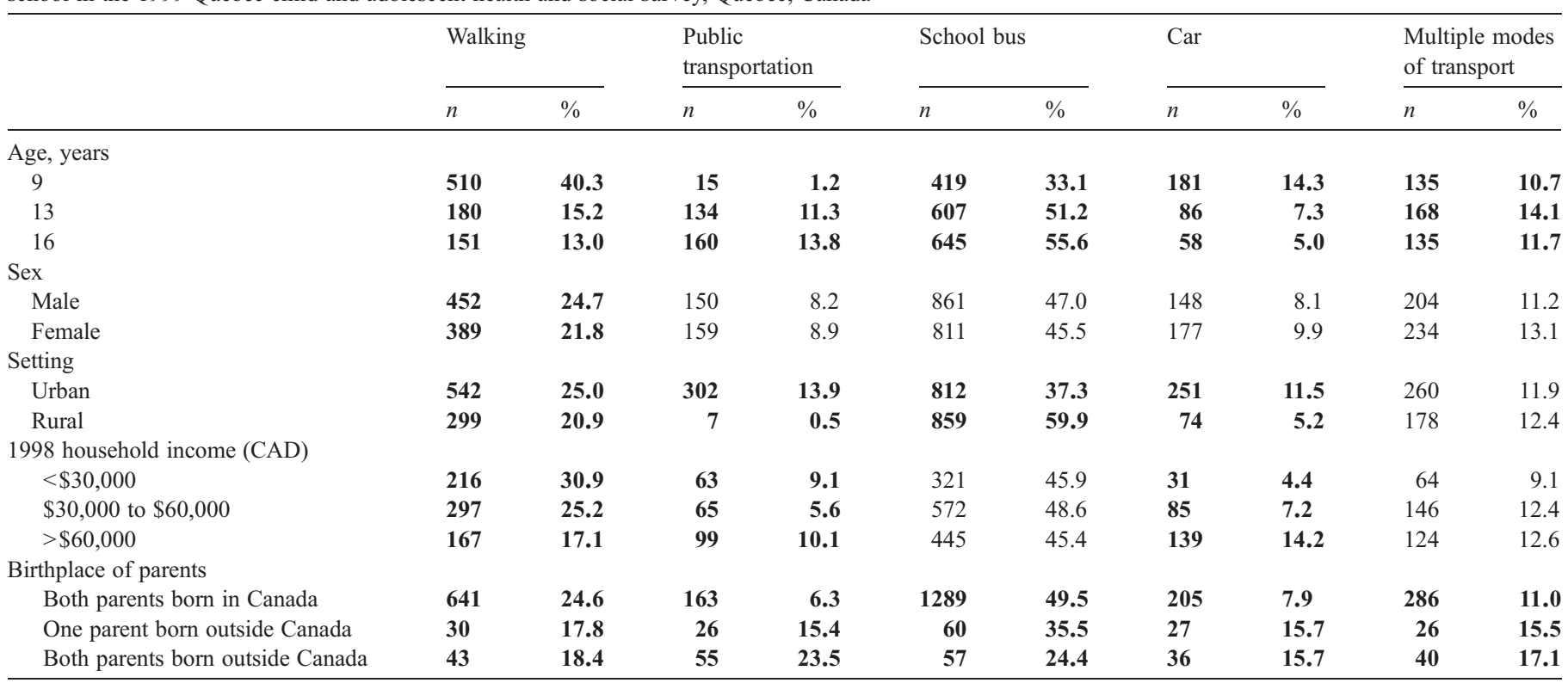

Numbers in bold represent statistically significant differences across strata as reported in the Results section.

and use multiple modes of transportation $\left(\chi^{2}=10.29, p<0.01\right)$ to school were significantly higher among children whose parents were not born in Canada.

\section{Discussion}

The purposes of this study were to establish the proportion of children who walked, used public transit, were driven in a school bus or vehicle, or used multiple transportation modes to school and to identify socioeconomic correlates. We observed that $40.3 \%, 15.2 \%$, and $13.0 \%$ of 9,13 , and 16 year olds walked to school. In comparison, a 2001 American nationwide study showed that $17 \%$ of $5-18$ year olds walked to or from school at least once during a usual week (Martin and Carlson, 2005). Another study using a representative population-based sample in Georgia established the proportion of 5-15 year olds engaging in active commuting to be less than 5\% (Bricker et al., 2002). Furthermore, $48.9 \%$ and $43.3 \%$ of this same sample took the school bus or were driven to school. Although these estimates appear to vary widely, it should be noted that methodologies differed substantially and classification of who walks to school were different. Moreover, estimates from existing studies are pooled across settings differing in urbanization which is likely linked to influential determinants such as of neighborhood safety, availability of public transportation, topography, and climate (Martin and Carlson, 2005; Merom et al., 2006).

This study's main strength is that it is a representative population sample, generalizable to Quebec, yielding valid proportion estimates of students using various modes of transportation to school. However, the current study does not account for the travel distance between home and school nor for weather variations across seasons, which are substantial in Quebec. Also, the response options did not include alternative modes of transportation such as cycling, skateboarding, or rollerblading.

The study findings indicate that more systematic observation of modes of transportation to school has relevance for local population surveillance and cross-settings comparisons. Researchers and public health practitioners can determine if target populations are using active modes of transportation to school and establish public health goals for active commuting among youth.

\section{Acknowledgments}

Roman Pabayo is a recipient of a Canadian Institutes of Health Research Institute of Population and Public HealthPublic Health Agency of Canada Doctoral Research Award (\#-81009) and is working under the supervision of Lise Gauvin. Data are from the Enquête Sociale et de Santé chez les Enfants et les Adolescents ESSEA, C Gouvernement du Québec, ISQ, 1999.

\section{References}

Barnett, T.A., O’Loughlin, J., Gauvin, L., Paradis, G., Hanley, J., 2006. Opportunities for student physical activity in elementary schools: a crosssectional survey of frequency and correlates. Health Educ. Behav. 33 (2), 215-232 (Apr)

Bricker, S.K., Kanny, D., Mellinger-Birdson, A., Powell, K.E., Shisler, J.L., 2002. School transportation modes-Georgia. MMWR 51 (32), 704-705 (August 16).

Carlin, J.B., Stevenson, M.R., Roberts, I., Bennett, C.M., Gelman, A., Nolan, T., 1997. Walking to school and traffic exposure in Australian children. Aust. N. Z. J. Public Health 21 (3), 286-292 (Jun).

Centers for Disease Control and Prevention. Youth risk behaviour surveillanceUnited States, 1993. MMWR CDC Surveill Summ 1994:44. 
Centers for Disease Control and Prevention. Youth risk behaviour surveillance. United States, 1993. MMWR CDC Surveill Summ 1998:47.

Ham, S.A., Macera, C.A., Lindley, C., 2005. Trends in walking for transportation in the United States, 1995 and 2001. Prev. Chronic. Dis. 2 (4), A14 (Oct).

Heelan, K.A., Donnelly, J.E., Jacobsen, D.J., Mayo, M.S., Washburn, R., Greene, L., 2005. Active commuting to and from school and BMI in elementary school children — preliminary data. Child Care Health Dev. 31 (3), 341-349 (May).

McDonald, N., 2007. Critical Factors for active school travel among lowincome and minority students: evidence from the 2001 National Household Travel Survey. Active Living Annual Conference. Coronado, California. Feb 22-24.

Malina, R.M., Bouchard, C., Bar-Or, O., 2004. Growth, maturation and physical activity. Human Kinetics, Champlain, I.L.

Martin, S., Carlson, S., 2005. Barriers to children walking to school or from school-United States, 2004. MMWR 54 (38), 949-952 (Sept).

Merom, D., Tudor-Locke, C., Bauman, A., Rissel, C., 2006. Active commuting to school among NSW primary school children: implications for public health. Health Place 12 (4), 678-687 (Dec).

Paradis, G., Lambert, M., O’Loughlin, J., et al., 2003. The Quebec Child and Adolescent Health and Social Survey: design and methods of a cardiovascular risk factor survey for youth. Can. J. Cardiol. 19 (5), 523-531 (Apr).

Rosenberg, D.E., Sallis, J.F., Conway, T.L., Cain, K.L., McKenzie, T.L., 2006 Active transportation to school over 2 years in relation to weight status and physical activity. Obesity (Silver Spring) 14 (10), 1771-1776 (Oct).

Salmon, J., Timperio, A., Cleland, V., Venn, A., 2005. Trends in children's physical activity and weight status in high and low socio-economic status areas of Melbourne, Victoria, 1985-2001. Aust. N. Z. J. Public Health 29 (4), 337-342 (Aug).

Sirard, J.R., Riner Jr., W.F., McIver, K.L., Pate, R.R., 2005. Physical activity and active commuting to elementary school. Med. Sci. Sports Exerc. 37 (12) 2062-2069 (Dec).

Story, M., Neumark-Sztainer, D., 1999. Promoting healthy eating and physical activity in adolescents. Adolesc. Med. 10 (1), 109-123. 